\title{
The history and science of Chongkukjang, a Korean fermented soybean product
}

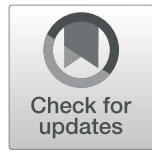

Dae Young Kwon ${ }^{1 *}$, Kyung Rhan Chung ${ }^{2^{*}}$ and Dai-Ja Jang ${ }^{1}$

\begin{abstract}
With several thousands of years of tradition, Chongkukjang is one of Korea's most well-known fermented soybean foods. Chongkukjang has existed in Korea since the first century BC and throughout the Koryo dynasty and kingdom of Silla, while si (豉, Chongkukjang) in Chaeksong was highly regarded according to the customs of Balhae. The fact that Koreans are good at creating fermented foods (善藏釀) is recorded in Samkukjiwijidongijeon (Records of the Three Kingdoms, 三國志魏志東夷傳), and Chongkukjang has been in Korea even longer than its 2000-year history in China. Chinese documents dating back to before 40 BC contain records of Chongkukjang or a similar fermented bean. Si does not originally come from China and was introduced to the country by an individual called Kang Baik (康伯) who is thought to have hailed from Korea, and there were many names for Chongkukjang in pure Korean such as jyeonkuk, cheongkuk, chyeonkuk, and chyeongkuk.

In short, Chongkukjang has existed as a fermented soybean food in Korea for more than 2000 years. However, some scholars have been distorting the truth and spreading false information about Chongkukjang. Some of these claims include "Chongkukjang was first created during wartime, as it could be prepared quickly," "Chongkukjang was introduced to Korea via the Qing dynasty," and "The first documented record of Chongkukjang in Korea is in Junbosallimkyongje(增 補山林經濟), written by Yu Jung-im (柳重臨) in 1760." If these claims were true, the Chongkukjang would be less than 400 years old. However, these theories are mostly put forward by scholars who are familiar with Chinese characters but know nothing about natural science or food science. By examining Korean history purely through the analysis of Chinese characters, which is indicative of the toadyish attitude of such scholars, they have committed the error of misrepresenting Korean food culture and history. Instead of looking at the history of Chongkukjang through the character si (豉), they claim that the only references to Chongkukjang in ancient texts are words written in Chinese characters (煎豉醬, 戰國醬, 青局醬, 青䴹醬, or 清國醬). How did this happen? Analysis of these documents can be used to demonstrate how these scholars came up with the baseless claim that Chinese characters, 煎豉醬, 戰國醬, 靑局醬, 青麥米醬, or 淸國醬, refer to Chongkukjang, instead of the names that were actually used (jyeonkuk, cheongkuk, chyeonkuk, and chyeongkuk), and how they inadvertently relegated Chongkukjang to the position of a food that has only existed in Korea for less than 400 years. Before Korean script (Hankeul, 한글) was developed, Chongkukjang was pronounced jyeonkuk, cheongkuk, chyeonkuk, or chyeongkuk and was referred to as si (豉) in official records which were written in Chinese characters. After the advent of Korean script, Chongkukjang was recognized as a kind of jang alongside doenjang (soybean paste), kanjang (soy sauce), and kochujang (red pepper paste), which is why the character jang (醬) was added as a suffix. Scholars then created the words 煎豉醬, 戰國醬, 青局醬, 青䴹醬, and 清國醬 by selecting Chinese characters that represent the pronunciation of jyeonkuk, cheongkuk, chyeonkuk, and chyeongkuk and adding the character jang to the end of each. This kind of mistake is understandable. However, these scholars have taken it further to the point that their interpretation, based on a false understanding of the way in which Chinese characters were used to spell out Korean words phonetically, has distorted the history and origins of Chongkukjang.
\end{abstract}

Keywords: Chongkukjang, Fermented soybean foods, History, Health, Origin of words

\footnotetext{
*Correspondence: dykwon@kfri.re.kr; chung311@aks.ac.kr

${ }^{1}$ Korea Food Research Institute, 245 Nongsaenmyung St, Iseo-myun,

Wanju-kun, Jeollabuk-do 55365, Republic of Korea

${ }^{2}$ The Academy of Korean Studies, Songnam, Kyongki-do, Republic of Korea
}

(c) The Author(s). 2019 Open Access This article is distributed under the terms of the Creative Commons Attribution 4.0 International License (http://creativecommons.org/licenses/by/4.0/), which permits unrestricted use, distribution, and reproduction in any medium, provided you give appropriate credit to the original author(s) and the source, provide a link to the Creative Commons license, and indicate if changes were made. The Creative Commons Public Domain Dedication waiver (http://creativecommons.org/publicdomain/zero/1.0/) applies to the data made available in this article, unless otherwise stated. 


\section{Introduction}

Humans have no system for storing food within their bodies so that it can be eaten later. Accordingly, the history of food science focused on the question of how leftover food could be preserved for later consumption. Although the methods for obtaining and eating food are also important, it is this question that formed the foundation of developments in food science.

In ancient times, there was no clear logic for answering this question, so each culture took a different approach. Because people did not have any clear principles to follow, they adopted a process of trial and error to learn which foods did not cause illness or death, and this empirical science gradually evolved into food culture over hundreds and thousands of years [1]. However, when viewed from the lens of modern food science, the question of whether food could be eaten at a later date ultimately came down to whether the changes that occurred made it edible or inedible and whether bacteria caused it to go rotten and make people sick. Of course, some foods were toxic, a lesson which was learned through experience when people perished after eating them.

Although our ancestors had no understanding of the concept of microorganisms, they realized that washing, cooking, drying, or pickling food with salt or sugar allowed it to be stored for a longer period of time before consumption. From the perspective of modern science, we now know that these processes reduce water activity $\left(\mathrm{a}_{\mathrm{w}}\right)$, stopping microorganisms from growing and thereby preventing rotting [1]. Although these methods are old, they are actually very scientific when viewed in this modern knowledge. But perhaps what is more surprising is not that people were able to prevent microorganisms from growing, but that they learned how to let bacteria grow in a way which would produce edible food. The origins of this can be seen in yoghurt in the West, and foods like kimchi and Chongkukjang in the East. Because our ancestors did not know about microorganisms, they could not have known the difference between rotting and fermentation, or the fact that both processes are caused by bacteria. However, it is clear that they were able to distinguish between the two, as this is the difference between food that is edible and food that makes people sick. In ancient times, people adopted a cultural approach to preparing and eating food because they had no understanding of the scientific processes.

This is why the cultural and historic properties of ethnic foods are an important part of understanding them scientifically. The science of our ancestors is embedded within history and culture. Across many cultures around the world, alcoholic beverage is the main fermented product. This includes wine in the West, liquor in the East, and makgeolli in Korea. In Korea, there are several methods for brewing traditional alcohol. In the West, fermented foods came to prominence through the wine, cheese, and yoghurt traditionally made by nomads, while in the East, an agrarian style of living led to the development of fermented grains or vegetables. Kimchi is a fermented food made with vegetables that is unique to Korea. Koreans were able to create such a unique fermented food (kimchi document, ethnic) because of their 5000 years of agricultural history. There are 200-300 different varieties of kimchi in Korea, and kimchi was included on a list of the world's top five health foods in an article published in Health in 2006 [2]. Also included on the list were yoghurt and soy products, which are also fermented. Accordingly, although fermented foods were developed long before developments in science, they are now scientifically recognized as health foods. Traditional scientific analysis in the West believed that all microorganisms were bad for the body, but it is now known that many bacteria contained in food, especially the lactic acid bacteria found in kimchi and yoghurt, have a number of health benefits. This means that fermented foods are valued for their biological health benefits as well as their traditional cultural value. Our gut health is greatly influenced by the foods we eat, in particular fermented foods [3].

Now that there is a greater focus on fermented foods, a lot of misinformation about the history and origins of Chongkukjang has been disseminated. These claims, which largely come from non-scientific disciplines, have not been properly examined or verified and are rooted in the narrow-mindedness of scholars who study ancient documents. This is unavoidable in an information society, but fake news, false information, and incorrect knowledge are problematic and cause a lot of harm. In the past, people could turn to newspapers, TV news, or print media for reliable information, but nowadays, there is a lot of fake news packaged in the same way, causing some to mistake fact for fiction and amplify the problem by spreading it. Fake news and information diminishes the power of truth and prevents accurate information from spreading, which is why it is so sinister. The public and consumers have the right to know the truth. In modern times, one of the greatest duties of the state or nation is separating fact from fiction and providing accurate information to citizens to build a healthy and trustworthy society.

Recently, Chung published a paper in which he translated ancient documents about the history of Chongkukjang and used this as evidence to refute some high profile wrong theories about the food [4]. It was a very well-written paper based on written evidence [4]. Accordingly, in this paper, the authors aim to examine the history of fermented foods around the world to shed light on why the claims put forward by some scholars are unscientific and explain these theories have taken root, as well as correct common misconceptions about the history, origins, and value of Chongkukjang. 


\section{Chongkukjang and similar foods around the world}

In many Asian countries, particularly Korea, the traditional diet consists mostly of grains and vegetables, making protein deficiency a common problem $[5,6]$. This is why Koreans ate a lot of soy products to supplement their diet. Soybeans come from Manchuria [7] and have been eaten in Korea for a long time. Koreans added protein to their diet by roasting and eating soybeans directly or using them to make tofu. Soybeans are also used to make Chongkukjang or Chigae (see [6]) with soybean paste, as well as other dishes. In short, soybeans are a very important food in Korea.

Chongkukjang is one of Korea's most well-known fermented foods. It is made by fermenting soybeans after boiling. Unlike doenjang (soybean paste), kochujang (red pepper paste), and kanjang (soy sauce), which require several months of fermentation [8, 9], Chongkukjang only takes 2-4 days to ferment. After harvesting soybeans in autumn, they are washed, boiled, and left to cool. They are then placed in the warm part of a room on a basket or clay pot covered with straw, covered with a blanket to regulate the temperature, and left to ferment for 2-3 days [8,9]. The fermenting agent is Bacillus, as most of the strains involved in the fermentation of Korean Chongkukjang come from straw. Chongkukjang is a classic example of a fermented soybean food that does not contain salt. Since Chongkukjang has been eaten in Korea for a long time, it makes sense that the food has several thousands of years of history. Japanese natto, a type of Chongkukjang that originated in Korea, has also been around for several thousands of years. Natto is an improved version of Chongkukjang that has become a global food, but its origins lie in Korea. Chongkukjang in Korea is usually eaten as a Kuk (like soup) and Chigae [6], while in Japan, natto was allowed to be eaten on its own after inoculating the strains.

There are also foods similar to Korean Chongkukjang found in Southeast Asia and South Asia. Some examples are douchi from Sichuan, China, kinema from Nepal and India, and fermented soybeans from countries on the Indochinese Peninsula, including Thai thuanao [10]. Nakao, a Japanese scholar, refers to kinema, natto, and thuanao as the "KNT triangle" [11], but since the three pillars of this food group are Korean Chongkukjang, Nepalese kinema, and thuanao from the Indochinese Peninsula, the name "Chongkukjang belt" makes more sense than KNT triangle. This also includes sieng from Cambodia and pepok from Myanmar [10]. These fermented foods are mainly produced through Bacillus fermentation. In countries such as Indonesia and Malaysia, which were formerly part of the Santara dynasty [12], there is also a food that closely resembles Chongkukjang called tempeh. Although similar, tempeh is not part of the "Chongkukjang belt" because fermentation in tempeh is mainly caused by mold such as Rhizopus or Aspergillus, and yeast such as Saccaromyces. Of course, bacteria such as Lactobacillus also play a role in producing tempeh, but the majority of fermentation takes place through mold or yeast [13].

Of course, our ancestors were not able to distinguish between bacteria and mold, so it was the same logic that led to the discovery of Chongkukjang and tempeh. Although the same principle of fermentation applies to Chongkukjang, which was developed in northern countries, and tempeh, which was developed in southern countries, it is sufficient to understand that mold and yeast were mainly responsible for the fermentation of Chongkukjang in humid countries located further to the south. The variation in Chongkukjang-based dishes between countries can be explained by the differences in each culture's ethnic foods.

\section{Chongkukjang's history and culture}

Korea has a farming culture with more than 5000 years of history. Although Korea is close to China in geographic terms, the country possesses its own unique history and culture. Prior to the foundation of the Qing dynasty, China was led by ethnic groups especially the Han (漢) Chinese, during the Three Kingdoms and the Jin, Tang, and Ming dynasties. During this period, Korea was inhabited by an Altaic people (of Mongolian descent) and developed its own distinct language and history. The progression of Korean history passes through KoChosun (古朝鮮) and the Three Kingdom period of Kokuryo (高句麗), Baekje (百 濟), and Silla (新羅), which was followed by Koryo (高麗) and the Chosun (朝鮮) dynasty. During this period, the country remained separate from China, which led to its distinct history and culture. The Korean language is also part of the Altaic family which includes Manchuria (formerly Kokuryo), Mongolia, Japan, Hungary, and Finland. This linguistic system is quite different from that of China. In ethnologic terms, Koreans can be distinguished from Chinese through the Mongolian spot that they share with Mongolians. Although there are some misconceptions that Korean culture is derived from China, Korean culture developed separately from that of China in both geographic and ethnologic terms. Accordingly, Korea also has its own unique food culture which greatly differs from China [14].

However, many scholars in Chinese characters and the humanities mistakenly believe that China and Korea share the same food culture. Chinese culture can be represented by "Hwangha Culture" (黃河文化, Hwanghe Culture, Yellow River culture), while Korean culture is a “Lyoha Culture" (遼河文化, Liaohe Culture, Liao River culture) from the plans of Manchuria [15]. These two cultures differ in biological, archaeological, linguistic, and cultural terms. These differences are exemplified through the Mongolian spot, comb-pattern pottery, and Altaic language. Genetic analysis has even shown the 
different DNA structure of people from the Yellow River and Liao River ethnic groups [16]. Nevertheless, many scholars continue to regard Korean culture as a part of Yellow River culture. This is because Yellow River culture had a written script and left many records in Chinese characters, while Liao River culture did not have a system of writing. Accordingly, relics are the only remnants of Liao River culture. This is why scholars believe that Korean culture can be found in ancient records, which are written in Chinese characters. Their perceptions of Korean culture are distorted by the fact that the records they refer to are written in Chinese script. In other words, even though there are clear differences between the origins and foods of Korea and China, some scholars seek to study the history of Korean culture and foods through documents written in Chinese characters, as there are very few such records written in Korean script. They believe that records written in Chinese characters can account for Korean food culture.

Korean food culture is very different from that of China. Instead of placing blind faith in records written in Chinese script to shed light on Korean food culture, it makes more sense to consider which parts of Korean culture were recorded in this way. Analyzing ancient documents from this perspective is conducive to providing a more accurate understanding of Korean food culture. Korean food culture can only be understood by starting from the assumption that Chinese character records are incomplete or contain a number of errors.

This paper seeks to examine records about Chongkukjang from this perspective. Taking a look at the records about Chongkukjang in old Chinese documents is only one way and useful for drawing inferences about the history of Korean Chongkukjang. The first step is determining how the word Chongkukjang would have been written in Chinese script.

The first documents written in Hankeul (Korean script) were Hunminjeongeum (訓民正音) and Hunminjeongeum Haerye (訓民正音解例). Since Korean script was first created in 1443 and promulgated in 1446, it cannot be found in any other record from around the world. Once Korean script was introduced, it was easy to write words as they sound, so producing written records became a lot easier. However, because Chinese script was used up until this point, a dictionary is required to determine how the Korean language was written using Chinese characters and which Korean words certain Chinese characters written before the advent of Korean script refer to. There are several such dictionaries made under the King's orders, including Hunmongjahoe (訓蒙字會, 1527) [17] by Choi Se-jin, a linguistic scholar, as well as Naehun (內 訓) [18] and Ojenaehun (御製內熏) [19]. Hunmongjahoe was created to help children learn Chinese characters, while Naehun and Ojenaehun were written to teach women in the palace.In Hunmongjahoe, Chongkukjang is referred to as $s i$ (豉), as seen in jyeonkuk si (from the Japanese Naegakmungobon, 1527), chyeonkuk si (Gyujangkakbon, 1613), and chyeonkguk si (Hankyebon, after 1660) [4]. This demonstrates that this fermented soy bean dish (Chongkukjang) was called jyeonkuk, chyeonkuk, or chyeongkuk at the time and also that the character si (豉) was used to refer to it (Fig. 1: Naegakmunkobon, Hankyebon, Gyujangkakbon). Since Hankeul had not yet been invented before this time, it appears that this character was chosen because it refers to a similar food in China. It is undisputable that Chongkukjang was called jyeonkuk, chyeonkuk, or chyeongkuk in ancient times. In documents published after Hunmongjahoe, such as Saeuikyonghombang (四醫經驗方, 1608) (Fig. 2a) [20] and Donguibogam (東醫寶鑑, 1610) (Fig. 2b) [21], Chongkukjang is referred to as chyeongkuk and yakjyeonkuk, respectively. This provides further evidence that the dish called Chongkukjang today was formerly known as cheongkuk. In addition to this, the fact that Chongkukjang is recorded in Chinese character dictionaries like Hunmongjahoe demonstrates that Koreans have been eating the dish for a very long time, because the food itself must have existed prior to the

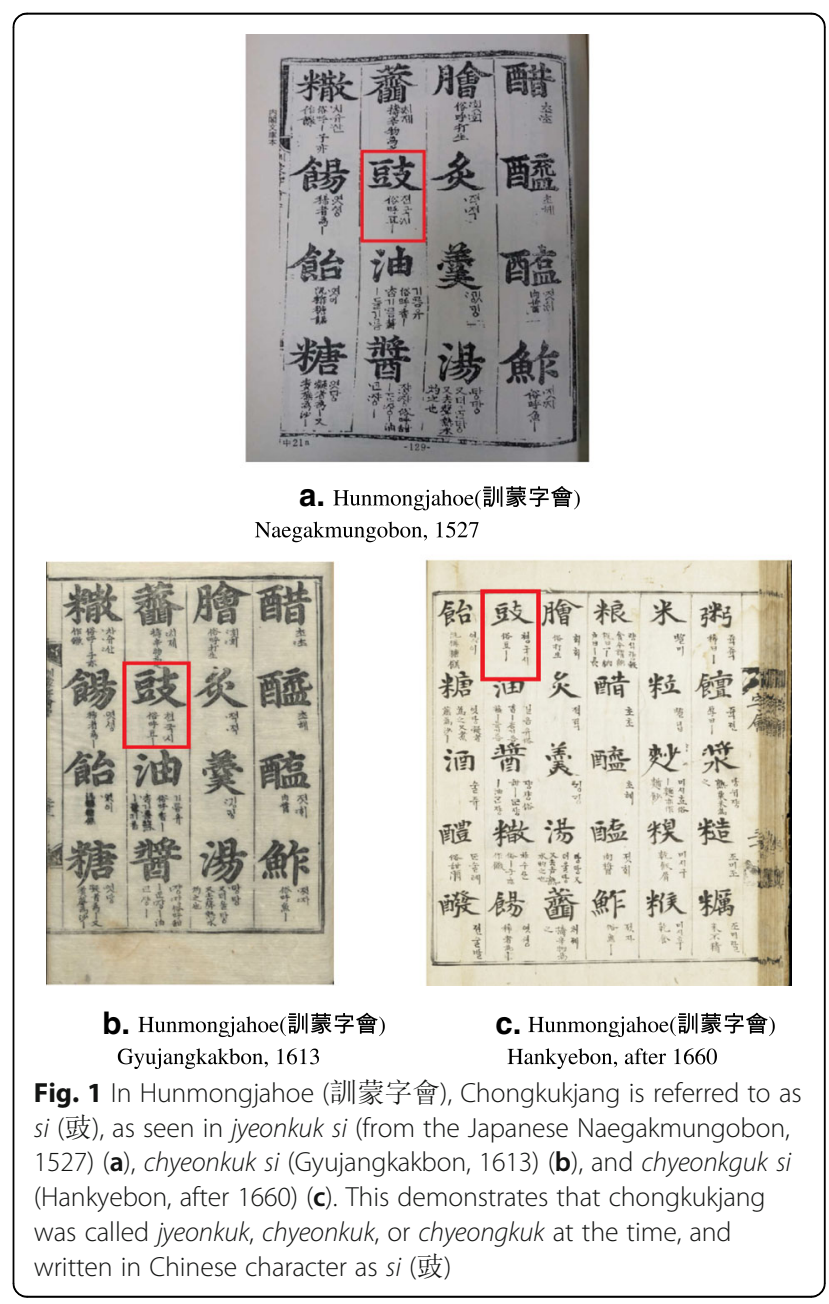




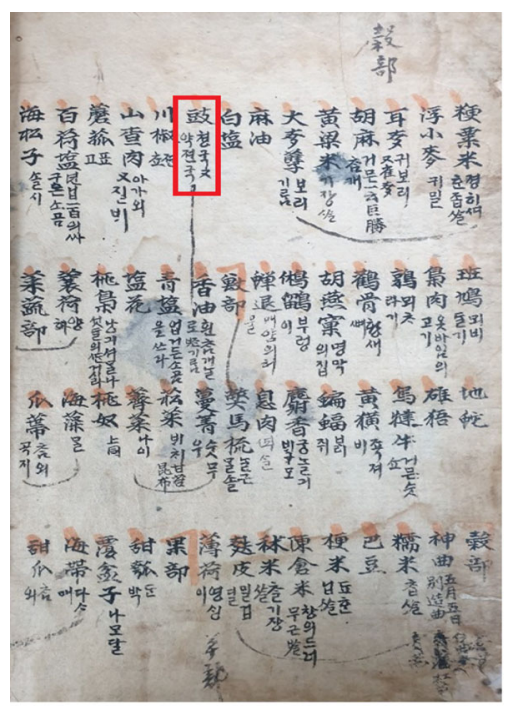

a.

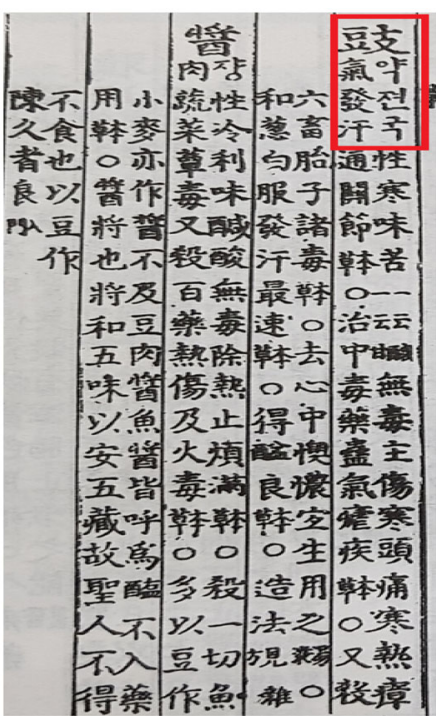

b.

Saeuikyonghombang (四醫經驗方, 1608) Donguibogam (東醫寶鑑, 1610)

Fig. 2 In documents published after Hunmongjahoe, such as Saeuikyonghombang (四醫經驗方, 1608) (a) and Donguibogam (東醫寶鑑, 1610) (b), Chongkukjang is referred to as chyeongkuk and yakjyeonkuk, respectively. This provides further evidence that the dish called Chongkukjang today was formerly known as cheongkuk for the long times. Chongkukjang was also written as si (鼓) in Chinese character as

point when written records were first kept. Examination of records written in the 200-300 years after the invention of Korean script show that Chongkukjang was no longer called cheongkuk, and the word jang had been added to the end of the word. For example, in Oju-YeonmunjangjeonSanko (五洲衍文長箋散稿, 1788-1849) [22], si (豉) was called jeonkukjang (戰國醬) or jeonsijang (煎鼓醬) (Fig. 3a), while jeonsijang (煎鼓醬) was called chyeongkukdyang in Bakhaetonggo (博海通放, 1700) (Fig. 3b) [23], and the dish was referred to as cheongkukjang (青麥米醬) and chyeongkukjang in Saryubakhae (事類博解, 1855) (Fig. 3c) [24]. While the original name for Chongkukjang was cheongkuk or jeonkuk, at some point, the suffix jang was added to create the word that is used today. As people began to view Chongkukjang as another kind of jang alongside doenjang, kanjang, and kochujang, the names chyeongkukdyang and chyeongkukjyang emerged, and because there was a need to put this name into Chinese characters, jang was added as a suffix and the word was recorded as jeonsijang (煎鼓醬), jeonkukjang (戰國醬), cheongkukjang (靑局 醬), or cheongkukjang (靑麥匊醬). A closer examination reveals that there is no logic to these coined words, and they were simply created by different people based on personal preference.

As described above, the Chinese character si (豉) was originally used to refer to Chongkukjang. Accordingly, analysis of the history of Chongkukjang should focus on this character $(s i)$, as it was the original word used for Chongkukjang prior to the advent of Korean script. There is no way of knowing whether si was chosen because of the existence of
Chongkukjang or another similar food in China, but it is clear that this character refers to Korean Chongkukjang in Korean records. The words jeonsijang (煎豉醬), jeonkukjang (戰國醬), and cheongkukjang (靑麴醬) do not appear in Chinese documents because they were created in Korea to refer to Korean Chongkukjang. This means that inferences can be drawn about the history of Chongkukjang by analyzing the use of $s i$ in old Chinese documents.

Referring to Chinese documents written in Chinese characters is the only way to further trace the origins of Chongkukjang because there are no such documents written in Korean script. The oldest Chinese record available is Kupchwipyun (Jijiupian, 急就篇, 40 BC) [25] from the Han dynasty. In this document, there is a reference to a dish called yeomsi (鹽鼓) (Fig. 4a) that appears to be similar to Chongkukjang, while in Solmunhaeja (Shuowenjiezi, 說文解字 (100 AD)) [26], a dish called baeyeomyusuk (配 鹽幽菽) is described which is made by seasoning soybeans with salt and sealing them away for a long time. In Bakmulji (Bowuji, 博物誌) [27], a compendium written by Zhang Hua (張華, 232-300 AD) during the Jin dynasty, a method for making si (鼓) in foreign countries is described, claiming that the recipe was passed down from barbarians by Kang Baik (康伯) (Fig. 4b) [27]. Si (鼓) is referred to as baeyeomyusuk in Bonchokangmok (Bencaogangmu, 本草綱目), written by Li Sijin (Li Shizhen, 李時 珍, 1518-1593) [28], and this text also attributes the food to a person called Kang Baik. Yonkamlyuham (Yuanjian Leihan, 淵鑒類函), written by Zhang Ying (張英, 16371708) [29] repeats the content about si found in Bakmulji 


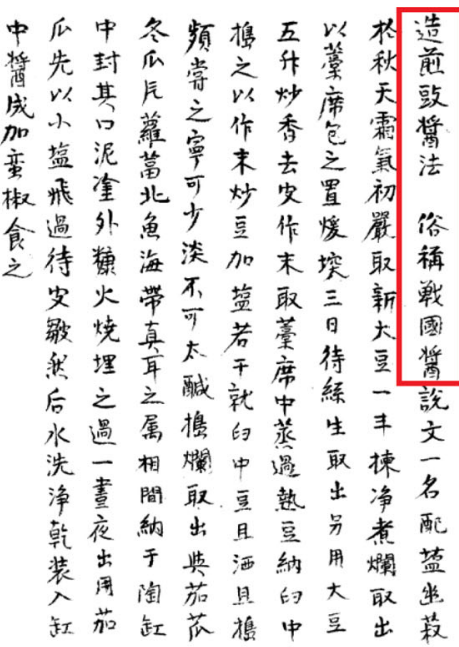

a-1

Oju-Yeonmunjangjeon-Sanko

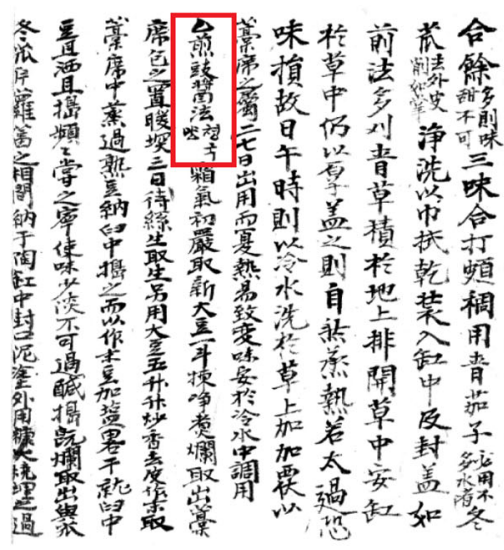

b. Bakhaetonggo (博海通放, 1700)

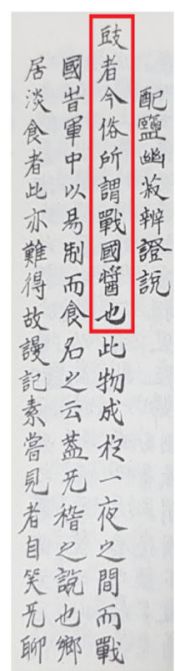

a-2

(五洲衍文長箋散稿, 1788-1849)

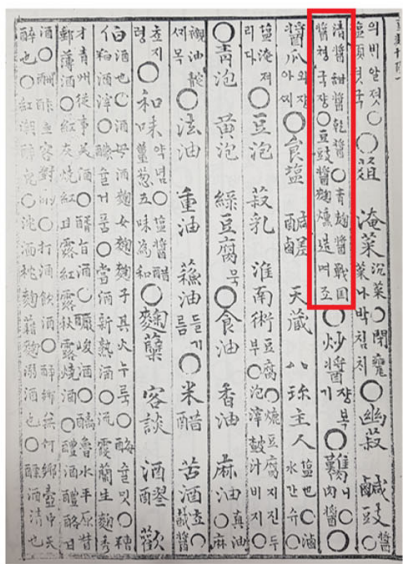

C. Saryubakhae (事類博解, 1855)

Fig. 3 a Oju-Yeonmunjangjeon-Sanko (五洲衍文長箋散稿, 1788-1849) shows that si (豉) was called jeonkukjang (戰國醬) or jeonsijang (煎豉醬). b Bakhaetonggo (博海通敃, 1700) shows Chongkukjang was called as chyeongkukdyang and written as jeonsijang (煎豉醬). c Saryubakhae (事類 博解, 1855) shows that Chongkukjang was called as chyeongkukjang and written as cheongkukjang (青䴹醬). All these documents showed that modern chongkukjang is the same that as those 500 years ago

claiming that $s i$ is good for the body and originates from Shandong Province (Fig. 4c) [4].When put together, this evidence suggests that si existed in China as early as 40 $\mathrm{BC}$ and that it was introduced to China by a person called Kang Baik from a barbarian tribe like as Korea. There is no way of knowing whether this barbarian hailed from Korea (Dongi, 東夷) or a nearby country such as Indonesia (Namman, 南蠻). However, Yonkamlyuham states that the food is originally from Shandong Province, and since Chinese Chongkukjang ferments through the same Bacillus bacteria as Korean Chongkukjang, it is likely that the origin is closer to Korea than a more southern country like Indonesia or Malaysia, where tempeh ferments through mold or yeast. In any case, it appears that there was a dish very similar to Chongkukjang in Dongi (東 夷), a dynasty that existed in Korea's current location, while tempeh, a food that is also similar to Chongkukjang, existed in Namman (南蠻). This suggests that this old document is rooted in truth. Accordingly, it can be extrapolated that Chongkukjang originally came from a foreign land and was introduced to China more than 2000 years ago. This can also be inferred from the fact that a kind of Chongkukjang called si (豉) has been around for a long time in China as well.

\section{Misconceptions about Chongkukjang}

Most of the misconceptions about Chongkukjang have been created and perpetuated by scholars 


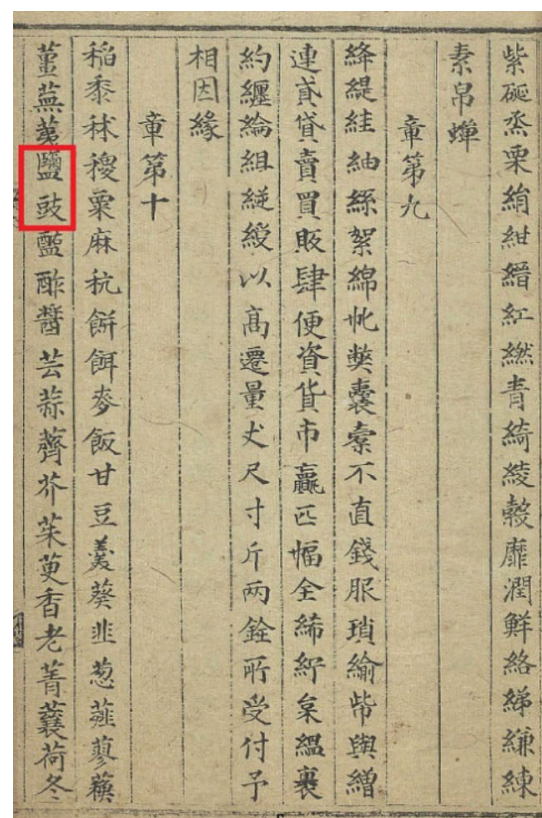

a. Kupchwipyun (急就篇)

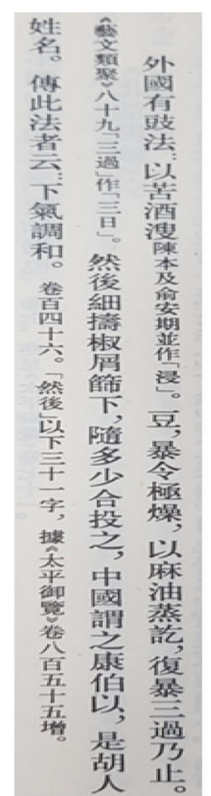

b. Bakmulji

(博物誌)

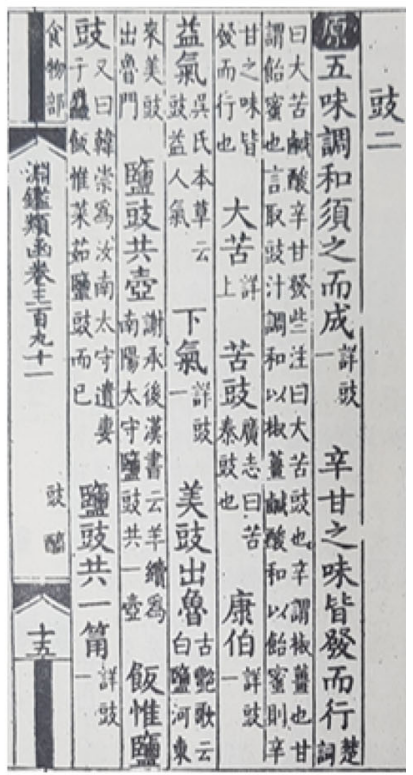

c. Yonkamlyuham (淵鑒類函)

Fig. 4 In China many documents showed that there is a similar product to Chongkukjang after imported from foreign countries. a Chinese record, Kupchwipyun (Jijiupian, 急就篇, 40 BC) [25] from the Han dynasty, shows that yeomsi (鹽豉) which is similar to Chongkukjang appears. b In Bakmulji (Bowuji, 博物誌), a compendium written by Zhang Hua (張華, 232-300 AD) during the Jin dynasty, a method for making si (鼓) in foreign countries was described, claiming that the recipe was passed down from barbarians by Kang Baik (康伯). c Yonkamlyuham (Yuanjian Leihan, 淵鑒類函), written by Zhang Ying (張英, 1637-1708), repeats the content about si found in Bakmulji, claiming that si is good for the body and originates from Shandong Province

familiar with Chinese characters. Furthermore, since many of these scholars are university professors or authors of books, everyday people tend to treat their word as right. However, those who study food scientifically have been left out of the discussion. This means that the harm caused by any mistake or untruth is difficult to rectify, which is compounded by the fact that these scholars are regarded as authorities on the matter and have published a number of books and dictionaries that are used as reference materials by many people.

"The Standard Korean Language Dictionary [30]" published by the National Institute of Korean Language states that Chongkukjang (清䴹醬) is A type of jang made by placing boiled soybeans in a hot room and grinding them before adding salt and red pepper paste. Chongkukjang is mainly eaten as a stew;
From a broad perspective, this definition is not incorrect. However, although there is no way of verifying which persons were involved in writing this definition, it appears to be a humanities scholar with little knowledge of foods. This is because anyone who has ever made Chongkukjang will know that the food does not contain any salt or red pepper powder. Salt and red pepper paste are only added when Chongkukjang is boiled in a chigae. There is a lot of inaccurate information like this, even in dictionaries which are recognized by the government as authoritative.

In addition to this, the Encyclopedia of Korean Culture, a publication painstakingly produced by the Academy of Korea Studies, one of national-funded research institute, states that Chongkukjang is a type of jang that is also called jeonkukjang (戰國醬, literally 'war country jang') because it can be made in a short period of time during

“(장의 한 가지로 삶은 콩을 더운 방에서 띄워 반쯤 찧다가 소금과 고춧가루를 넣어 만드는 데, 주로 찌개를 꼻여 먹는다)" 
times of war. It is also called cheongkukjang (淸國醬) because it was introduced from the Cheong (Qing) dynasty, as well as jeonsijang (煎鼓醬). The first reference to Chongkukjang in Korea was in Junbosallimkyongje (增補 山林經濟), written by Yu Jung-im (柳重臨) in 1760 [31].

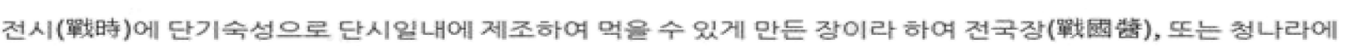

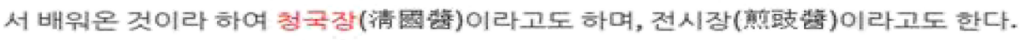

청국장이 문헌에 처음 보인 것은 1760 년(영조 36 ) 유중임(柳重臨)에 의하여 보강된 "증보산림경제

The person in charge of writing the entries about foods in this encyclopedia is Lee Seong-woo, the scholar who spread the false information that red chili peppers were introduced to Korea during the Japanese invasions in the 16th century [32, 33]. As a food scientist familiar with Chinese characters, many of Lee's claims about Korean food culture are based on books written in Chinese characters, and he has been responsible for distorting the truth about Korea's food culture with inaccurate information. Lee most likely wrote this entry after seeing records of jeonsijang (煎鼓醬) and jeonkukjang (戰國 醬) in Junbosallimkyongje. He makes no mention of si (豉), the original word that was used to refer to Chongkukjang in written records, although it is unclear whether this is because he did not look for such records or passed over any that he found. Even if Lee is correct that the words jeonsijang and jeonkukjang refer to Chongkukjang, the statement that the first reference to Chongkukjang in Korea was in Junbosallimkyongje [34] by Yu Jung-im's is clearly and totally incorrect. Jeonkukjang (戰國醬) is mentioned in a number of documents produced before Junbosallimkyongje, including Hujae (厚齋) [35] and Hujaesonsaengbyuljip (厚齋先生別集) [36] by Kim Gan (金畭, 1646-1732) (Fig. 5a). It is also referenced

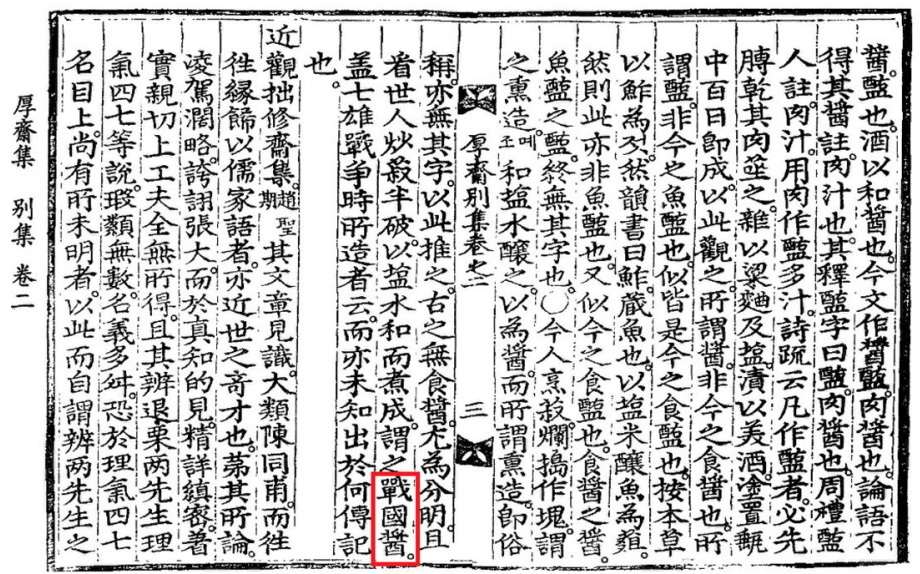

a. Jungbosalimkyongje(增補山林經濟)

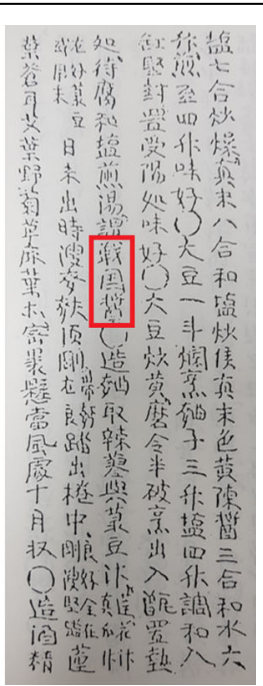

b. Chisaengyoram

Fig. 5 Many non-scientific scholars, like as Lee Seong-woo, claims that first book where Chongkukjang is written as Jeonsijang (煎豉醬) is in Jungbosalimkyongje(增補山林經濟), but there are a number of documents produced before Junbosallimkyongje in which Jeonsijang (煎豉醬) and Jeonkukjang (戰國醬) are mentioned. a Hujaesonsaengbyuljip (厚齋先生別集) by Kim Gan (金榦, 1646-1732) showed Jeonkukjang (戰國醬). b Chisaengyoram (治生要覽) written by Gang Wa (强窩) in 1691 also showed Jeonkukjang (戰國醬). Both jeongukjang and chyeonggukjang also feature in Bakhaetongko (博海通敃) (see Fig. 3b) 
in Chisaengyoram (治生要覽) [37] written by Gang Wa (强窩) in 1691 (Fig. 5b), and both jeongukjang and chyeonggukjang also feature in Bakhaetongko (博海通敃) [38], which was written at the beginning of the eighteenth century (Fig. 3b). Despite the fact that the Chinese character 清 (cheong) in Chongkukjang, which represents the Qing dynasty, was never used in any documents from the Chosun dynasty, Lee even claims that Chongkukjang was given its name because it was introduced to Korea via the Qing dynasty. Without even conducting a proper examination of these ancient documents, he has spread false and unscientific information that has distorted the truth about Korean food culture. Lee also makes no mention of the fact that Jyeonkukjang was written in Korean script in Eumsikdimibang (閨 閫是議方, 1670) [39], which was released long before the publication of Junbosallimkyongje. There is no evidence in ancient records to support his entries in the Encyclopedia of Korean Culture. Fabricating claims without any evidence is a typical pattern found in individuals who wish to appear scholarly.

Since government-endorsed publications like this contain inaccurate information, it leads to even greater harm when the same false claims are repeated in materials printed by the private sector as well. Unfortunately, Lee and his followers have done a great disservice to Korean food culture. One example is the entry on Chongkukjang in the Doosan Encyclopedia, which is based on the Donga Encyclopedia (doopedia: http://www.doopedia.co.kr/ doopedia/master/master.do?_method=view\&MAS_ IDX $=101013000860952$ ). The full entry reads as follows;
“Chongkukjang [清麥匊醬]: A type of Korean soybean paste made by placing soft boiled soybeans in a hot place to stimulate the production of Bacillus Subtilis. The first reference to Chongkukjang in Korea is jeonkukjang (戰 國醬), which was recorded in both Sallimkyongje (增補 山林經濟), written in the mid-Chosun dynasty, and Jungbosallimkyongje (增補山林經濟). The word used for Chongkukjang differs slightly between books, with jeonkukjang written in Oju-Yeonmunjangjeon-Sango (五洲 衍文長箋散稿) and cheongyukjang used in Gyuhapchongseo (閏閤叢書). In some regions, it is also called dambukjang. There are several theories about the origins of Chongkukjang, but the two leading theories about soybean foods are a) that they are derived from the original form of $s i$ (豉), and b) that jang eaten by the Qing dynasty's army during the Manchu War of 1636 was introduced to Korea and came to be called Chongkukjang (or jeonkukjang). It appears that Chongkukjang became popular because it could be prepared quickly during wartime due to its short fermentation period."

This is indicative of the quantity of misinformation that ordinary Koreans are regularly exposed to, and needs to be rectified. The Doosan Encyclopedia also claims that Chongkukjang was usually written as 清䴹醬 (Chongkukjang) in ancient documents, when in fact this name was hardly used at all. In fact, in addition to the false claim that the Chinese characters for Chongkukjang are 清國醬, Lee also lists the word 清麥米醬, which implies that the food ferments through mold. In short, all of this information is wrong, because Korean Chongkukjang ferments through Bacillus rather than mold. Even worse, the Doosan Encyclopedia also refers to Chongkukjang as doenjang (soybean paste) or Korean Doenjang. The name "Korean doenjang" implies that soybean paste originated from outside Korea. It can be

\footnotetext{
청국장[淸䴳醬]

무르게 익힌 콩을 뜨거운 곳에서 납두균이 생기도록 띄워 만든 한국 된장.

청국장이 우리나라 문헌에 처음 등장한 것은 조선 중기의 (산림경제(山林經濟)〉와 〈증보산림경제(增補山林經濟)〉에 기록된 ‘전국장(戰國獎)'이다. 청국장을 일컫는 말은

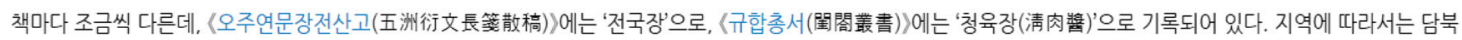
장이라고 부르기도 한다. 청국장의 유래에 대해서는 여러 가지 설이 있으나 두장류의 가장 초기적인 형태인 시(攱)에서 유래되었다는 설과 17세기 병자호란 때 청나라 군 대의 식량으로 쓰이던 장이 유입되어 이때부터 청국장(또는 전국장)이라고 부르게 되었다는 설이 있다. 이는 아마도 전쟁 중에 장이 익을 때가지 오랫동안 기다릴 수 없어 바로 만들어 먹을 수 있는 속성장의 형태로 청국장이 생겨난 것으로 보인다.

청국장은 영양분이 많고 소화가 잘 되는 식품이다. 배양균을 첨가하면 하루 만에 만들어 먹을 수 있다. 자연발효에 의한 청국장은 메주콩을 $10 ~ 20$ 시간 더운 물에 불렸다 가 물을 붓고 푹 꼻여 말씬하게 익힌 다음 보온만으로 띄운 것이다. 그릇에 짚을 몇 가닥씩 깔면서 퍼담아 $60{ }^{\circ} \mathrm{C}$ 까지 식힌 다음 따뜻한 곳에 놓고 담요나 이불을 씌워 보온 하면 바실러스균이 번식하여 발효물질로 변한다. 바실러스균은 $40 ~ 45^{\circ} \mathrm{C}$ 에서 잘 자라며, 발암물질을 감소시키고 유해물질을 흡착해서 몸 밖으로 배설시킨다. 바실러스 균은 공기 중에도 많이 있지만 볏짚에 많이 들어 있으므로 청국장을 띄울 때 콩 사이사이에 볏짚을 넣고 띄우면 매우 잘 뜬다.
} 
true? As discussed above, the fermentation process and fermenting agent for Chongkukjang are strictly different from those of doenjang [8], which makes this argument a non-starter. This kind of error would never have taken place if these encyclopedias were written by food scientists. It appears that some scholars are fond of fabricating information which does not align with scientific facts, as these claims appear plausible when not subjected to close scrutiny, making the author look learned and scholarly. The argument that Chongkukjang "appears to have been created during times of war because it could be prepared quickly due to its short fermentation period" was fabricated to add credibility to Lee's theory that the food's origins lie in war. Although this story was shaped by other scholars to fit with the war and Qing dynasty narrative, it is simply an absurd claim.

This kind of unscientific misinformation has been widely disseminated across a number of websites, including the Doosan Encyclopedia, and has been compounded by the fact that people are easily persuaded by the arguments of scholars in Chinese characters who pretend to know what they are talking about.

\section{References to Chongkukjang in ancient literature}

As mentioned above, despite the existence of many records over thousands of years which refer to Chongkukjang using the word $s i$ (鼓), some scholars continue to look only at records in which the Chinese characters for Chongkukjang are written as jeonsijang (煎鼓醬), jeonkukjang (戰國醬), cheongkukjang (靑局醬), or cheongkukjang (青䴹醬). However, looking at such records does not present an accurate picture of the history of Chongkukjang. This can only be achieved through an examination of the records about si. A paper by Chung on records about Chongkukjang in ancient Korean documents contains a detailed chronological chart [4].

Korea is a Liao River-based culture that has its origins in Kochosun (古朝鮮) and Kokuryo (高句麗). Chung found that yeomsi (鹽豉) and si (豉) were referred to in Deokheungri Gobun (a cave painting, 408 AD) [15], as well as History of the Three Kingdoms (三國史記) [40], which recorded the period from the first century to 668 AD during Kokuryo, and Haedong History (海東繹史), which describes the customs during the Balhae period (698-926 AD) [41]. This demonstrates that Chongkukjang already existed during Kokuryo.

Chung [4] also uncovered two records that confirm Chongkukjang existed in Silla in the record of History of the Three Kingdoms (三國史記) [40]. One is from 671 AD (the 11th year of King Munmu's reign) from Silla and describes an incident the food, yeomsi (鹽豉), was run out, because the road to Woongjin was blocked off, while the other record from $683 \mathrm{AD}$ (the 3rd year of King Sinmun's reign) appears to include $s i$ in a list of traditional wedding ceremony foods. The fact that Chongkukjang was around during the Kokuryo and Silla periods, alongside evidence that Chaekseong (柵城) si (Chongkukjang) was highly regarded in the customs of Balhae, which was founded by migrants from Kokuryo, is strong evidence that the food has been eaten in Korea since before the Three Kingdom period in the first century. In this sense, Chung's paper is very scientific. It proves that the claim in New Tang's History (新唐書, 1044-1060) [42] that si (鼓) came from Dongi (東夷) is factual, and if Balhae's Chaekseong si was already wellknown at this point, it is likely that the food had already existed in Korea for several thousands of years before the publication of Jijiupian $(40 \mathrm{BC})$, the first Chinese document that contains a record of $s i$.

Chung's paper [4] uses records contained in ancient documents to make the case that Chongkukjang existed in Korea during the Koryo kingdom. Based on records contained in Haedong History (海東繹史) [41] and Dongkukyisangkukjip (東國李相國集, 1241) [43], Chung demonstrates that Chongkukjang was added to kuk (see in [44]) during the Koryo kingdom (916-1392), and also notes that Chongkukjang was an important part of providing famine relief to the starving people in History of the Koryo Dynasty (高麗史) [45].

Medical books including Hyangyakgugeupbang (鄉藥 救急方, 1236) [46] and Hyangyakjipseongbang (鄉藥集 成方, 1433) [47] also state that adding Chongkukjang to kuk can help to relieve fever. In particular, the latter book describes how si (鼓) was added to lotus root kuk to treat people who were babbling or feeling dizzy because of a chest fever, and also contains records of $s i$ being used to treat other illnesses.

In documents after 1443, when Korean script (Hankeul) was invented, si (豉) is written in Korean script, which shows that Chongkukjang was pronounced jyeonkuk, chyeongkuk, or chyeonkuk (Hunmunjahoe, 訓蒙字 會), (the Japanese Naegakmunkobon, 1527), (Gyujangkakbon, 1613), (Hankyebon, after 1660) [17], Sauigyeongheombang (四醫經驗方, 1608) [20], and Donguibogam (東醫寶鑑, 1610) [21]. It is meaningless to discuss which of these words is correct, because there was no standard version of Korean at the time. Although there was a pure Korean word for Chongkukjang, it does not appear in written records even after the advent of Hankeul. Instead, cheongkuk was recognized as a type of jang and gradually became known as Chongkukjang, so when it became possible to write records in Hankeul, Chinese characters were coined to refer to each Hankeul sound. Since Chongkukjang was treated as a king of jang alongside doenjang, kanjang, and kochujang, the character jang (醬) was added as a suffix, and the dish was called Chongkukjang from that point onwards. This is how Chinese words for Chongkukjang as “戰國醬,”“煎鼓醬, “靑局醬, “靑䴹醬,” 
and “清湯醬” were written (Hujaeseonsaengbyeoljip, 厚齋 先生別集, 1646-1732) [36], Bakhaetongko（博海通改, after 1700) [23], Oju-Yeonmunjangjeon-Sango (五洲衍文 長箋散稿, 1788-1849) [22], Dyeongniuigwe (整理儀軌, 1796) [48], Ilseongrok (日省錄, 1796) [49], and Sarubankhae (事類博解) [24]. Even though the word Chongkukjang could easily be written in Korean script, they want to try to write Chongkukjang in Chinese characters. There were no official Chinese characters for Chongkukjang because Chongkukjang is native Korea language; therefore, it appears that different individuals fabricated their own characters for it based on their interpretation of the word's meaning, which led to the variations and mistakes.

References to Chongkukjang written in Korean script begin to appear in documents about 100 years after the advent of Hankeul, with the first record found in Hunmongjahoe [16]. In Eumsikdimibang (1670) [39], it was written as jyeonkukjyang. In Bakhaetonggo (博海通改) [23], the word chyeongkukdyang is used, while it is referred to as chyeongkukjyang in Dyeongniuigwe (整理儀 軌, 1796) [48] and cheongtangjang (清湯醬) in Siuijeonseo (是議全書, 1890) [50] because the dish was mainly eaten as a tang (湯, see [44]). Lee Seong-woo and his followers believe that Chongkukjang must have been written in Chinese characters, and refuse to recognize records written in Korean script. This attitude is misguided and rooted in dogma.

It is even more regrettable that in the period surrounding Korea's liberation from Japanese occupation, a number of scholars recorded Chongkukjang as 清麥甸醬 in the Chosun eo Sajeon (朝鮮語事典, Korean Language Dictionary) (1938) [51] and Keun Sajeon ( , "big dictionary," published by the Korean Language Society in 1957) [52]. They appear to have reached the conclusion that it makes no sense to have several different Chinese character versions for the same Korean word. Unfortunately, they based their decision on the inaccurate information that Chongkukjang was introduced from the Qing dynasty, and attempted to add some science to the endeavor by adding the character for mold ( $k u k$, 麴). In science, Chongkukjang is not fermented by mold but bacteria. Although this appears valid at first glance, it is unscientific and rooted in the belief at the time that Chongkukjang had come from Chinese characters. The scholars were unable to see past their prejudice that Chinese characters were of greater importance than Korean script.

Even in Oju-Yeonmunjangjeon-Sanko [22], it is written that " $\mathrm{Si}$ (鼓) is currently called jeonkukjang, and was given this name because it can be made overnight and was easy to prepare in the palace during times of war. However, there is no evidence to support this claim (豉 者。今俗所謂戰國醬也。此物成於一夜之間。而戰國 時。軍中以易制而食。名之云。蓋無稽之說也)"
The book also states that Chongkukjang only appeared after the Han dynasty (則蓋自漢以來。始有之也). Even during Lee Kyu-gyeong's day in the eighteenth century, there were people spreading misinformation about Chongkukjang due to their toadyish attitude; the widespread misconception is Chongkukjang was developed during wartime because of easy preparing. Hujaeseonsaengbyeoljip (厚齋先生別集, 1646-1732) [35] also states that Chongkukjang (戰國醬) was created during the Seven Kingdoms War (七雄戰爭) (1046 BC to 220 $\mathrm{AD})$. In other words, the food was created during the period where the Seven Kingdoms fought for control of China [53]. Whether this is true or not, it suggests that Chongkukjang was around as early as $200 \mathrm{BC}$, which would give the dish at least 2200 years of history. It appears that this sentence was used as the basis for the belief that Chongkukjang was created during wartime, without giving it a broad interpretation. However, the theory that Chongkukjang was called jeonkukjang (戰國 醬) because it was easy to prepare during times of war [54] is unsupported by evidence. This was the belief of Lee Gyu-gyeong, the author of Oju-Yeonmunjangjeonsanko [22]. He also recognized Chongkukjang was related on the war, which was totally wrong. There are also many references to Chongkukjang and si (豉) in documents from the Chosun dynasty [4] which demonstrate that it was a very common food in people.

\section{Why is there so much misinformation about Chongkukjang?}

And why do these claims continue to be repeated and supported? Of course, many would claim that the etymology of Chongkukjang is not that important. But the truth of birth and etymology of Chongkukjang are so important. If it were true that the name Chongkukjang is borrowed from China, then the word's etymology would be rooted in China, especially Qing (淸) Dynasty, and an examination of records of jeonkukjang (戰國醬) or cheongkukjang (清國醬) from the point when si was first written would lead to the conclusion that the history of the food only amounts to several hundreds of years. In this case, it would be true that Chongkukjang was originally introduced from China or another country, and it could even have been created during the Qing dynasty in the 1600s. This is similar to the disservice that has been done to Korean red pepper paste, kimchi, and dakdoritang (chicken stew) by the absurd theory that Korean red peppers were introduced to Korea during the sixteenth century Japanese invasions $[6,55]$. Despite the existence of clear records that refer to red chili peppers (椒) and kimchi (菹) thousands of years ago, the misconception that only the Chinese character-based words kocho (苦椒) and chimchae (沉菜) refer to these foods in documents published after the invention of 
Korean script has led some to believe that red chili peppers have only been around in Korea for 500 years, and kimchi for only 100 years [56]. In recent time, the advent of the 4th Industrial Revolution and big data has added a layer of super-connectivity to the world which means false information can have a wide-reaching adverse impact. This affects the globalization and advancement of Korean foods and must be stamped out [14].As is the case with red chili peppers and kimchi [32, 56], most of the misconceptions about Chongkukjang have been created and perpetuated by scholars familiar with Chinese characters. Furthermore, since many of the scholars who make these statements are university professors or authors of books, everyday people tend to believe what they say without critical scientific examination. This means that the harm caused by any mistake is difficult to rectify.

Although it is not the majority, some Korean scholars familiar with Chinese characters develop a sense of selfimportance and like to show off their knowledge. They are very proud of their ability to decipher the meaning of texts written in Chinese characters. In the modern world, facts and science are an integral part of true communicating information, but these scholars refuse to acknowledge scientific data. In short, they are plagued by a toadyish attitude. Based on the false belief that the etymology of Korean words lies in Chinese characters, they limit their research to studying such texts as Chinese text. As stated in an earlier section, Korean culture is Liao River-based, while China is rooted in Yellow River culture. Accordingly, the etymology of Korean words can be found in Altaic tribes such as the Jurchen, Mohe, Khitan, Göktürks, Balhae, and Mongols. Although languages that belong to this family still exist in Hungary, Finland, and Mongolia, many of these tribes have unfortunately disappeared. The roots of the Korean language should be understood through Korean which was based on these tribes. In other words, attempting to trace the etymology of a word like Chongkukjang is a fruitless endeavor, just as it would be for other pure Korean words like saram (person), namu (tree), or sokeum (salt) because they did not have their own script although they have their own languages. There are no ancient documents written in Korean script that detail the history of Chongkukjang before invention of Hankeul (Korean script).

Of course, it would be impossible for such records to have been written before the creation of Korean script in 1443, but even after this point, most educated aristocrats preferred to write in Chinese characters because they looked down on Korean script as a writing system developed for commoners and women. It is difficult to write Korean in Chinese script because the languages are different, while writing words as they sound in Korean script (a phonetic script) is far easier and more accurate.
Accordingly, the fact that so many old Korean documents were written in Chinese characters (an ideographic script) leads to many errors because it is almost impossible to convey meaning and sound accurately. This is why caution is required when speaking about Korean history as seen through Chinese character records. Focusing purely on analyzing Chinese character records while ignoring what was actually happening and speaking in Korea will naturally lead to a lot of errors in old literature written in Chinese character. This means the circumstances surrounding such records need to be taken into account to obtain an accurate picture of Korean food culture. However, since Korea was liberated from Japan, a number of scholars including Lee Seongwoo have adopted this approach without a complete understanding about the nature of foods; Korea's food culture and history have severely distorted Lee Seong-woo $[32,57]$. They claim that the Chinese characters cheongkukjang are used to refer to Chongkukjang. This is why they trace the history of Chongkukjang by examining records of cheongkukjang (清國醬) or similar Chinese characters, instead of focusing on records about si (豉) .In short, the Korean ethnic foods known as jyeonkuk, chyeonkuk, or chyeongkuk were referred to as si (豉) in written records prior to the advent of Korean script, while a number of different characters including 煎豉醬, 戰國醬, 青局醬, and 青麥粗醬 were written after the introduction of Korean script because a new Chinese character expression was required to match the phonetic sound of Chongkukjang. This is why Lee's claim that Chongkukjang did not exist in Korea until these character-based words appeared in documents is false, and this also explains why the history of foods such as red chili peppers, kimchi, and Chongkukjang have been misinterpreted. These theories have led to a lot of misinformation about Chongkukjang, distorting the food's history. Lee insists that red chili peppers were introduced to Korea through the sixteenth century Japanese invasions, and fabricated the claim that kimchi and red chili peppers did not exist in Korea prior to Chinese character records of these foods in order to justify his theory $[31,32]$. This is a classic example of a mistake that distorts Korean food history and culture. He skips over the fact that everything in Korea had existed for hundreds or thousands of years before writing was even invented.

\section{Why does the character si (豉) refer to meju (fermented soybeans block) nowadays?}

As discussed above, the character si (鼓) was used to refer to Chongkukjang in documents produced prior to the advent of Korean script in 1443, while the phonetic pronunciation of the dish was jyeonkuk, chyeongkuk, or chyeonkuk [17]. However, during the era when aristocrats looked down upon Korean script and preferred to 
write in Chinese characters, Chongkukjang came to be viewed as a type of jang similar to doenjang, kanjang, and kochujang and was written as 戰國醬, 靑局醬, 清䴹醬, or 煎豉醬, which is an unintentional mixture of several terms.

Meju, fermented soybean block for fermenting soybean, is a food made with soybeans for the purpose of making kanjang, doenjang, and kochujang $[8,9]$. Since this food did not exist in China, for a long time, it was written using the Chinese characters jangkuk (醬䴹) (Fig. 6a). At the time, the mold involved in the fermentation process of meju (Aspergillus) was correctly written as mold (kuk, 䴹). This suggests that even during this period, Koreans were able to distinguish between bacteria (gyun, 菌) and mold. In Hunmongjahoe (1527) [17], the word si clearly refers to Chongkukjang, while 醬䴹 refers to mуеоји (mејu). However, from the 1600s, when Chongkukjang began to be recorded as 戰國醬, 靑 局醬, 清䴹醬, or 煎豉醬, the character si (豉) was instead used to refer to meju or sometimes doenjang [58]. Doenjang was another food that did not exist in China. This is why the same word was used to refer to meju and doenjang. There are a number of references to meju in ancient comments. It is called myejo in Yeosaseoseonhae (女四書諺解，1737) (Fig. 6b) [59], or called myojo in Junbosallimkyongje（增補山林經濟，1766) [34], Uihwi

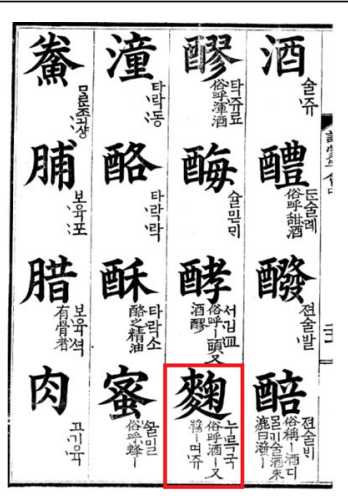

a. Hunmongjahoe (1527)

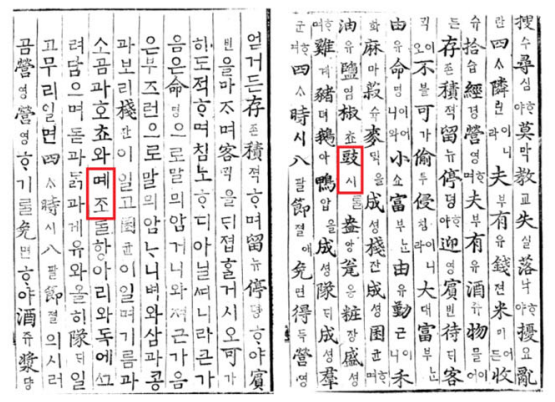

b. Yeosaseoseonhae (女四書諺解, 1737)

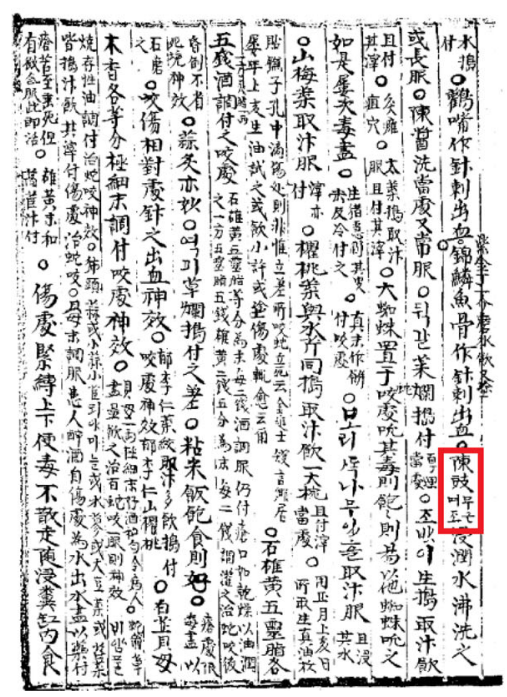

C. (Uihwi (宜彙, 1871)

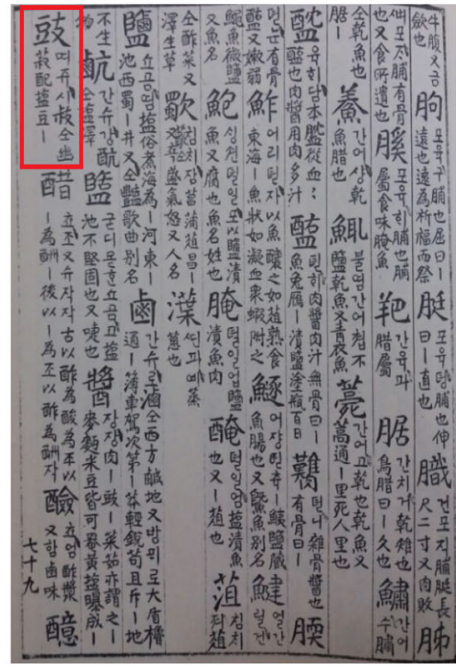

d. Jaryujuseok (字類註釋, 1856)

Fig. 6 ]. Meju did not exist in China; for a long time, it was written using the Chinese characters as jangkuk (醬麥米) (a). At the time, the mold involved in the fermentation process of meju (Aspergillus) was correctly written as mold (kuk, 䴴). This suggests that even during this period, Koreans were able to distinguish between bacteria (gyun, 菌) and mold. In Hunmongjahoe (a), the word si clearly refers to Chongkukjang, while 醬䴹 refers to myeoju (meju). However, from the 1600s, when Chongkukjang began to be recorded as 戰國醬, 青局醬, 清㛽醬, or 煎豉醬, the character si (豉) as instead used to refer to meju or sometimes doenjang. Doenjang was another food that did not exist in China. This is why the same word was used to refer to meju and doenjang. There are a number of references to meju in ancient comments. It is called myejo in Yeosaseoseonhae (女四書諺解, 1737) (b), or called myojo in Uihwi (宜彙, 1871) (c), Junbosallimkyongje (增補山林經濟, 1766), Yeoyudangjeonseo (與猶堂全書, 1762-1836) and Mulmyeonggo (物名放, 1820), and referred to as myeoju/myoju in Jaryujuseok (字類註釋, 1856) (d) and Jajeonseokyo (字典釋要, 1909) 
(宜彙, 1871) (Fig. 6c) [60], Yeoyudangjeonseo (與猶堂 全書, 1762-1836) [61], and Mulmyeonggo (物名敃, 1820) [62], and referred to as myeoju/myoju in Jaryujuseok (字類註釋, 1856) (Fig. 6d) [63] and Jajeonseokyo (字典釋 要, 1909) $[4,64]$. Uirimchwalyo (醫林撮要) [65] and Donguibogam (東醫寶鑑, 1610) [21] state that $s i$ (豉) refers to meju (末醬), while some later authors may have mixed up the expressions for Chongkukjang and meju by writing that si refers to doenjang in Chosunmussangsinsikyorijebeop (朝鮮無雙新式料理製法, 1924) [66] and Hanilseonsinokpyeon (韓日鮮新玉篇, 1935), or both meju and doenjang (Hanhandaesajeon, 1966) [4]. In particular, a distinction was drawn between Chongkukjang (煎鼓醬) and meju (豉) in Junbosallimkyongje (1766) (Fig. 7) [34]. This demonstrates that as early as the 1700s, the meaning of the character $s i$ had changed and begun to refer to meju.

$\mathrm{Si}$ was used to refer to Chongkukjang up until the 1500s, while using the Chinese character expressions 煎 豉醬, 戰國醬, and 清國醬 to refer to jyeonkuk, chyeongkuk and jeonkukjang in the 1600s entrenched 清䴹醬 as the written expression for Chongkukjang. Meanwhile, the meaning of si changed to meju or sometimes, doenjang after the 1600s due to aristocrats, usually men, who mixed up the expressions. In the period prior to the development of modern science, it was likely quite difficult to distinguish between Chongkukjang and meju, especially for men who had never made either of the dishes and spent their time writing instead. Because meju never existed in China, it appears that people were unable to find a suitable Chinese character for meju and ended up choosing si out of confusion between meju and Chongkukjang. The character $s i$ was later used exclusively for meju when other words for Chongkukjang were developed in the seventeenth century. However, the claim that all records of the character $s i$ after the seventeenth century refer only to meju is unsound from a literary perspective and entails the risk of mistranslation. Because the various words created for Chongkukjang (戰國醬, 靑局醬, 清麴醬, and 煎豉醬) were coined in Korea and are inaccurate, it is likely that some writers continued to prefer to use the original expression si for Chongkukjang. Food science analysis is required to determine whether each use of the character si refers to Chongkukjang or meju.

\section{The healthiness and safety of Chongkukjang}

As fermented foods are now believed to be healthy in most countries, there is greater interest in the functions of these foods. In Korea, a lot of research is being conducted into the functions of Chongkukjang. Through experiments on animals, it has been confirmed that Chongkukjang has an anti-inflammatory effect [67] and anti-diabetic effect [68]. As for the cause of this effect, differences in gene expression in the liver have been observed after eating Chongkukjang [69]. In other words, Chongkukjang has an impact on human health by causing changes in genetic expression and also influencing metabolism [70]. Other research has found that Chongkukjang promotes metabolism, has an anti-cancer effect, and helps to prevent stroke, hypertension, osteoporosis, and skin aging, while also relieving conditions such as constipation $[67,68,71,72]$. In recent studies involving
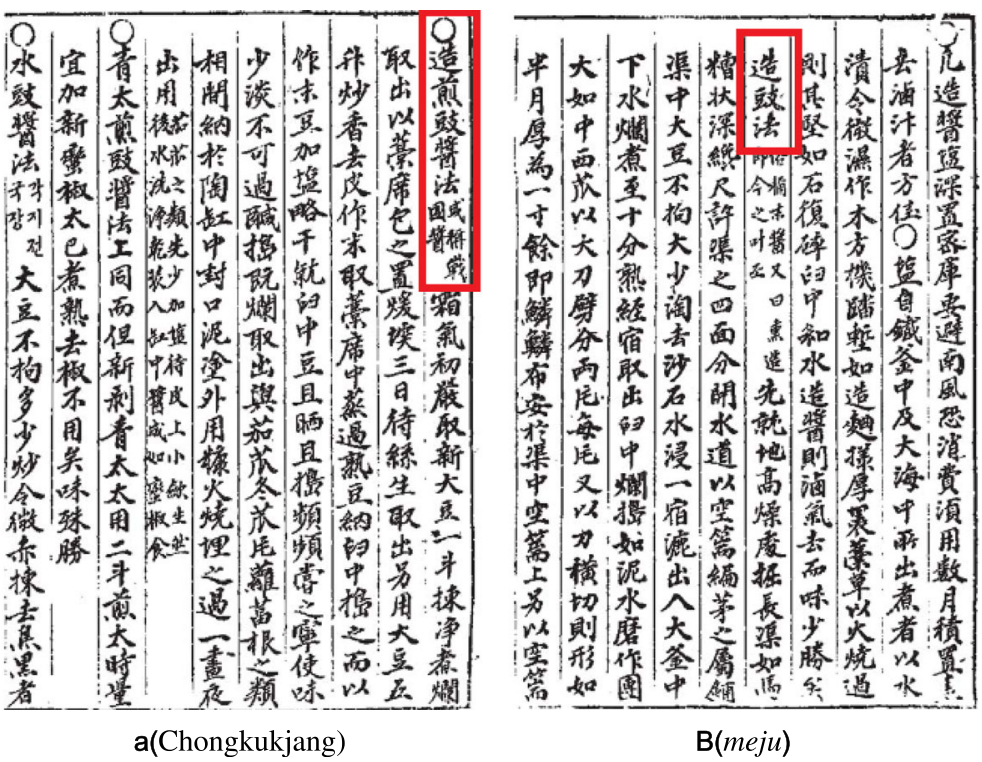

Fig. 7 After writing Chongkukjang as Chinese character (戰國醬, 青局醬, 清麴醬, 煎鼓醬), si (豉) refers to meju (末醬), although originally si refers to Chongkukjang. Thus, Yu in Junbosallimkyongje try to discriminate Chongkukjang (a) and meju (b) by a distinction drawn between Chongkukjang as Jeonsijang (煎鼓醬) and meju as si (鼓) 
human participants, it has also been confirmed that Chongkukjang has an anti-allergenic effect [72]. Records in Sikuisimgam (食醫心鑑, 800) show that Chongkukjang was prescribed for indigestion and stroke patients [73] and added to lotus root soup for people babbling or suffering from dizziness from a chest fever. In Hyangyakjipseongbang (㰾藥集成方, 1433), there are also records that claim Chongkukjang was used to treat illnesses [47].

Research on the health benefits of Chongkukjang is also taking place in other countries across Asia. One study from China found that douchi helps to reduce blood pressure [74]. Meanwhile, research on Indian kinema, which is similar to Chongkukjang, shows that the food contains antioxidant compounds, protein and peptide and a variety of amino acids and vitamins [75]. Natto, an improved version of Chongkukjang that was created when Korean Chongkukjang was introduced to Japan, has even been selected as one of the world's top five health functional foods [2].

But is Chongkukjang safe to eat? An interesting paper has been published that addresses this question. Bacillus is known to be the fermenting agent in Chongkukjang, but this study found that once fermentation begins, bacteriocins also play an equally important role in the process [71, 76]. In most fermented foods, salt is added to prevent harmful bacteria from growing, but this simply controls those bacteria rather than killing them. However, in kimchi, active components such as capsaicin (from chili peppers) kill other bacteria and ensure that only lactic acid bacteria are able to proliferate [77]. As a result of this, only lactic acid bacteria and other fermenting agents are able to grow, while proteins such as bacteriocins and peptides also appear to kill off other bacteria, leading to fermentation that produces edible food. In other words, fermentation in kimchi would not take place without red chili peppers [76]. This is why red chili peppers are an essential ingredient in kimchi. Kimchi could not exist without red chili peppers. Although it could still be pickled, this is different from fermentation. Jang discovered that the kimchicins, mejucins, and bacteriocins in kimchi and meju are the reason why kimchi and Chongkukjang are safe to eat [71]. Although Chongkukjang and kimchi have been eaten for thousands of years, this study shed light on the mechanism that makes them safe for consumption. Kimchi and red pepper paste are two examples of fermented Korean health foods that are safe to eat as long as they are not over-fermented [71, 76].

\section{Conclusion}

Chongkukjang is an indigenous fermented soybean food that has existed in Korea for thousands of years. However, some scholars have been distorting the truth and spreading false information about Chongkukjang. Some of these claims include "Chongkukjang was first created during war, as it could be prepared quickly," "Chongkukjang was introduced to Korea via the Qing dynasty," and "The first documented record of Chongkukjang in Korea is in Junbosallimkyongje (增補山林經濟), written by $\mathrm{Yu}$ Jung-im (柳重臨) in 1760 (the 36th year of King Yeongjo's reign)." If this were true, the dish, Chongkukjang, would be less than 400 years old. Chinese documents dating back to earlier than $40 \mathrm{BC}$ contain records of Chongkukjang or a similar stew called $s i$ (豉). $S i$ is not indigenous to China and was first brought there by an individual called Kang Baik (康伯) who hailed from a country that is thought to be Korea. There were many names for Chongkukjang in pure Korean such as jyeon$k u k$, cheongkuk, chyeonkuk, and chyeongkuk. In other words, Chongkukjang has existed as a fermented soybean food in Korea for almost 2000 years. However, a number of false claims about Chongkukjang have been made, mostly by scholars who are familiar with Chinese characters but know nothing about natural science or food science. By examining Korean history through the analysis of Chinese characters, which is indicative of the toadyish attitude of such scholars, they have committed the error of misrepresenting Korean food culture and history. Instead of looking at the history of Chongkukjang through the character si (豉), they claim that the only references to Chongkukjang in ancient texts are words written in Chinese characters. This theory is rooted in the belief that the history of Chongkukjang lies in the numerous variations of Chinese characters made to refer to the dish (煎豉醬, 戰國醬, 靑局醬, 青䴹醬, 淸國 醬 and 清䴹醬), while ignoring records of si (豉), the character that was originally used for Chongkukjang. The Korean public has fallen for this seemingly plausible explanation. Despite the clear differences between China and Korea in terms of history, language, and foods, these scholars in Chinese characters committed the error of seeking answers through 清國醬 or other similar combinations of characters.

Before Korean script was created, Chongkukjang was referred to as jyeonkuk, cheongkuk, chyeonkuk, or chyeongkuk and was written as si (豉) in official Chinese character records. After the advent of Korean script, Chongkukjang was recognized as a kind of jang alongside doenjang (soybean paste), kanjang (soy sauce), and kochujang (red pepper paste), which is why the character jang (醬) was added to the end. Accordingly, people created words like 戰國醬, 靑局醬, and 青麴醬 by selecting Chinese characters that represent the pronunciation of jyeonkuk, cheongkuk, chyeonkuk, and chyeong$k u k$ and adding the suffix jang to the end of each. However, these scholars have taken it further to the point that their interpretation, based on a false 
understanding of the way in which Chinese characters were used to spell out Korean words phonetically, has distorted the history and origins of Chongkukjang. This interpretation defies the available evidence. There is no evidence in ancient records to support the entry in the Encyclopedia of Korean Culture which not only claims that Chongkukjang is called jeonkukjang (戰國醬) because its short fermentation period allows it to be prepared quickly during times of war, but also that another name for the dish is cheongkukjang (清國醬) because it was introduced from the Qing dynasty. Many errors like this have been committed in Korean food culture, and they cause great harm. Correcting such misinformation is essential for rectifying the history of Korean food culture.

\section{Acknowledgements}

We would like to thank the funding support.

\section{Authors' contributions}

Authors contributed equally to conceive the study and write/revise the manuscript. All authors read and approved the final manuscript.

\section{Funding}

This work is supported in part of National Project of Platform for Information Service (GN160800).

\section{Availability of data and materials}

Not applicable.

\section{Competing interests}

The authors declare that they have no competing interests.

Received: 20 March 2019 Accepted: 27 May 2019

Published online: 17 July 2019

\section{References}

1. Kwon DY. Why ethnic foods? J Ethn Foods. 2015;2:91

2. World's 5 Healthiest Foods, March Issue 2006; Health Magazine.

3. Kau AL, Ahern PP, Griffin NW, Goodman AL, Gordon Jl. Nature. 2011;474: 327-36

4. Chung KR. The history of Chongkukjang. J Korea Contents Soc. 2018;18: 647-55.

5. Kim SH, Kim MS, Lee MS, Park YS, Lee HJ, Kang S-a, Lee HS, Lee K-E, Yang HJ, Kim MJ, Lee YE, Kwon DY. Korean diet: characteristics and historical background. J Ethn Foods. 2016;3:26-31.

6. Kwon DY, Kim SH, Kim MS, YE. What is Hansik (K-diet)? Seoul: Korea Food Research Institute; 2017. p. 14-68.

7. Hymowitz T. On the domestication of the soybean. Econ Bot. 1970;24:408-21.

8. Shin DH, Jeong D-y. Korean traditional fermented soybean products: Jang. J Ethn Foods. 2015;2:2-7.

9. Yang HJ, Park S, Pak V, Chung KR, Kwon DY. Fermented soybean products and their bioactive compounds, in soybean and health (Edited by $\mathrm{H} \mathrm{El-}$ Shemy); 2011. p. 21-58.

10. Tamang JP. Naturally fermented ethnic soybean foods of India. J Ethn Foods. 2015;2:8-17.

11. Nakao SM. Ryori no kigen. Japan: Japan Broadcast Publishing; 1972. p. 115-26.

12. Chavan SP. Santara Dynasty: Jainism in Southern Karnataka up to AD 1565 : DK Print world; 2005. p. 1-323.

13. History of soybeans and soyfoods in Southeast Asia (13th century to 2010) (compiled by W Shurtleff and A Aoyagi, Soyinfo Center, Lafayette. 2010; CA, USA.

14. Kwon DY. Hansik(K-diet) is the key to Centenarian Health, in Healthy Centenarian: Healthy Foods, Sikanyon. Seoul; 2019. p. 214-78.

15. Woo SH. Origin of Kochosun civilization and Lyoha culture, series of Kochosun civilization, vol. 3. Seoul: Jisik \& Industry; 2018.
16. Jin HJ, Kwak KD, Hammer MF, Nakahori Y, Shinka T, Kim W, et al. Ychromosomal DNA haplogroups and their implications for the dual origins of the Koreans. Hum Genet, 2010. 2003;114:27-35.

17. Choi SJ (崔世珍). Hunmongjahoe (訓蒙字會). In: Korea; 1527.

18. Queen Sohyon (昭惠王后). Naehun (內訓). In: Korea; 1475.

19. Anonymous. Ojenaehun (御製內訓). In: Korea; 1475.

20. Lee SG (李碩幹), Chae DG (蔡得己), Bak R (朴濂) and Heo I (許任) Saeuikyonghombang (四醫經驗方), Korea. 1608.

21. Heo K (許均). Donguibokam (東醫寶鑑). Korea. 1610.

22. Lee KG (李圭景). Oju-Yeonmunjangjeon-Sanko (五洲衍文長箋散稿). Korea. 1788-1849.

23. Anonymous. Bakhaetongko (博海通放). Korea 1700s.

24. Lee G (李公) Saryubakhae (事類博解). Korea. 1855.

25. Sa Y (史游). Keupchipyun (Jijiupian, 急就篇). China. 40 BC.

26. Hur S (许慎). Solmunhaeja (說文解字). China. 100 AD.

27. Jang H (張華). Bakmulji (博物誌). China. 200 s.

28. Li SJ (李時珍). Bonchokangmok (本草網目). China. p. 1596.

29. Zhang $Y$ (張英). Yonkamlyuham (淵鑒類函). China. p. 1710.

30. Standard Korean Language Dictionary ( of Korean Language, 1999, Seoul, Korea.

31. Yoon DI. Chongkukjang, Encyclopedia of Korean Culture, vol. 22. Seoul; 1991. p. 93.

32. Bae MH, Lee SW. Study on history of Kochu and its quality. Korea Dietary Style Science. 1984:187-201.

33. Lee SW. Kochu (red pepper chilli), Encyclopedia of Korean Culture, vol. 2. Seoul; 1991. p. 643-5.

34. Yu JI (柳重臨). Junbosallimkyongje (增補山林經濟). Korea. 1760.

35. $\mathrm{Kim}$ G (金翰). Hujae (厚齋). Korea. 1766.

36. Kim G (金翰). Hujaesonsaengbyuljip (厚齋先生別集). Korea. 1766 (Fig 5a)

37. Gang W (强窩). Chisaengyoram (治生要覽). Korea. 1691.

38. Anonymous. Bakhaetonggo (博海通㪀). Korea. :1700s.

39. Jang, K.H. (張桂香). Eumsikdimibang (閨閫是議方). Korea. 1670.

40. Kim BS (金富軾). Samkuksaki (三國史記). Korea. 1145.

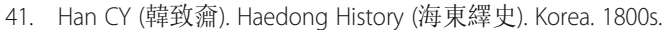

42. Gu YS (歐陽修), Song G(宋祁) et al. New Tang's History (新唐書). China. 1044-1060.

43. Lee GB (李奎報). Dongkukyisangkukjip (東國李相國集). Korea. 1241.

44. Kwon DY, Chung KR. Korean diets and their tastes. In: Park KY, Kwon DY, Lee KW, Park S, editors. Korean functional foods; composition, processing and health benefits. NY: CRC Press; 2018. p. 23-42.

45. Kim JS (金宗瑞). Jeong IJ (鄭麟趾). History of the Koryo Dynasty (高麗史) Korea. 1613.

46. Anonymous. Hyangyakgugeupbang (㰾藥救急方). In: Korea; 1236.

47. Yu HT (俞孝通). Noh JR (盧重禮), Park YD (朴允德). Hyangyakjipseongbang (曒藥集成方). Korea. 1433.

48. Anonymous. Jeongniuigwe (整理儀軌). In: Korea; 1797.

49. An JB (安鼎福). Ilseongrok (日省錄). In: Korea; 1796.

50. Anonymous. Siuijeonseo (是議全書). In: Korea; 1890.

51. Moo SY ((文世榮)). Chosuneo Sajeon (조선어사전). Korean Language Dictionary Publisher. 1938; Seoul, Korea.

52. Keun Sajeon (큰사전, big dictionary). Korean Language Society. 1957, Seoul, Korea.

53. The seven kingdoms were Qi (齊, 1046-379 BC) from the east, Chu (楚, ?-223 BC) from the south, Qin (秦, 221-206 BC) from the west, Yan (燕) from the north, and Wei (燕, 403-225 BC), Han (韓, 202 BC-220 AD) and Zhao (趙, 403-228 BC) from the central region.

54. Park Jeong-bae, Chongkukjang is food in the war because of easy fermentation (in Korean), http://premium.chosun.com/site/data/html_dir/ 2015/03/04/2015030400161.html), Premium Chosun, March 42015.

55. Kwon DY, Chung KR, Yang HJ. The truth of birth, propagation and evolution of Korean Kochu (chili). Seoul: Academy of Freedom; 2017.

56. Ju YH. Kimchi: Korean food. The culture and enthropology. Space. 1994; Seoil Korea (in Korean.

57. Ju YH. Kimchi: descendant of Changachi and Chanji. Pulmuwon Newsletter. 1999;69:18.

58. Choi YJ. A study on the characteristics of the Korean sauce 'Shi (豉)' in ancient Korean literature. J East Asian Soc Diet Life. 2017;27:684-93.

59. Lee DS (李德壽). Yeosaseoseonhae (女四書諺解). Korea. 1736 (Fig 6b).

60. Anonymous. Uihwi (宜彙). Korea. 1871 (Fig 6c).

61. Jeong YY (丁若鏞). Yeoyudangjeonseo (與猶堂全書). Korea. 1762-1836.

62. Jeong YY (丁若鏞). Mulmyeonggo (物名放). Korea. 1820， 
63. Jeong YY (鄭允容). Jaryujuseok (字類註釋). Korea. 1856 (Fig 6d).

64. Ja SY (池錫永). Jajeonseokyo (字典釋要). In: Korea; 1909.

65. Yang YS (楊禮壽). Uirimchwalyo (醫林撮要). Korea. p. 1500-1600s.

66. Lee YK (李用基). Chosunmussangsinsikyorijebeop (朝鮮無雙新式料理製 法). 1924, Seoul, Korea.

67. Choi YH, Lim H, Heo MY, Kwon DY, Kim HP. Anti-inflammatory activity of the ethanol extract of Chungkukjang, Korean fermented bean: 5-lipoxygenase inhibition. J Med Food. 2008;11. https://doi.org/10.1089/jmf.2007.0125.

68. Kwon DY, Daily JW, Kim HJ, Park S. Antidiabetic effects of fermented soybean products on type 2 diabetes. Nutr Res. 2010;30:1-13.

69. Soh JR, Kwon DY, Cha YS. Hepatic gene expression profiles are altered by dietary unsalted Korean fermented soybean (Chongkukjang) consumption in mice with diet-induced obesity. J Nutrit Metabol. 2011. https://doi.org/10 1155/2011/260214

70. Park MK, Cho IH, Lee S, Choi HK, Kwon DY, Kim YS. Metabolite profiling of Cheonggukjang, a fermented soybean paste, during fermentation by gas chromatography-mass spectrometry and principal component analysis. Food Chem. 2010;122:1313-9.

71. Chang HC. Healthy and safe Korean traditional fermented foods, kimchi and Chongkukjang. J Ethn Food. 2018;5:161-6.

72. Baek HI, Jung SJ, Ha KC, Kim HM, Choi EK, Park EO, Shin SW, Kim MG, Yun SK, Kwon DY, Yang HJ, Kim MJ, Kang HJ, Kim JH, Jeong DY, Joh SW, Cho BH, Chae SW. Effect of Chongkukjang on histamine-induced skin wheal response: a randomized, double-blind, placebo-controlled trial. J Ethn Foods. 2015;2:52-7.

73. Jam E (处殷). Sikuisimgam (食醫心鑑). Korea. 800 AD.

74. Zhang JH, Zhang ET, Ding C-H, Li L-T. Angiotensin I-converting enzyme inhibitory peptides in douchi, a Chinese traditional fermented soybean product. Food Chem. 2006;98:551-7.

75. Tamang JP. Himalayan fermented foods: microbiology, nutrition, and ethnic values. 1st ed. New York: CRC Press, Taylor \& Francis Group; 2010. p. 295.

76. Kwon DY. Scientific knowledge in traditional fermented foods. J Ethn Foods. 2018:5:153-4.

77. Kang BK, Cho MS, Park DS. Red pepper powder is a crucial factor that influences the ontogeny of Weissella cibaria during kimchi fermentation. Sci Rep. 2016;6:28232.

\section{Publisher's Note}

Springer Nature remains neutral with regard to jurisdictional claims in published maps and institutional affiliations.

Ready to submit your research? Choose BMC and benefit from:

- fast, convenient online submission

- thorough peer review by experienced researchers in your field

- rapid publication on acceptance

- support for research data, including large and complex data types

- gold Open Access which fosters wider collaboration and increased citations

- maximum visibility for your research: over $100 \mathrm{M}$ website views per year

At $\mathrm{BMC}$, research is always in progress.

Learn more biomedcentral.com/submissions 